\title{
Lymphohaematopoietic system cancer incidence in an urban area near a coke oven plant: an ecological investigation
}

\author{
S Parodi, M Vercelli, A Stella, E Stagnaro, F Valerio
}

Occup Environ Med 2003;60:187-194

See end of article for authors' affiliations ........................

Correspondence to: Dr M Vercelli, Department of Oncology, Biology and Genetics, University of Genoa, Ligurian Region Cancer Registry, c/o National Cancer Research Institute, Largo R. Benzi 10, 16132 Genoa, Italy; vercelli@p380. ist.unige.it

Accepted 10 July 2002

\begin{abstract}
Aims: To evaluate the incidence risk of lymphohaematopoietic cancers for the 1986-94 period in Cornigliano, a district of Genoa (Italy), where a coke oven is located a few hundred metres from the residential area.

Methods: The whole of Genoa and one of its 25 districts (Rivarolo) were selected as controls. The trend of risk around the coke oven was evaluated via Stone's method, while the geographic pattern of such risks across the Cornigliano district was evaluated by computing full Bayes estimates of standardised incidence ratio (FBE-SIR).

Results: In males, elevated relative risks (RR) were observed for all lymphohaematopoietic cancers (RR $1.7 v$ Rivarolo and $1.6 v$ Genoa), for NHL (RR $2.4 v$ Rivarolo and $1.7 v$ Genoa), and for leukaemia (RR $2.4 v$ Rivarolo and $1.9 v$ Genoa). In females, statistically non-significant RR were observed. In males no excess of risk was found close to the coke oven. In females, a rising risk for NHL was observed approaching the plant, although statistical significance was not reached, while the risk for leukaemia was not evaluable due to the small number of cases. Analysis of the geographic pattern of risk suggested the presence of a cluster of $\mathrm{NHL}$ in both sexes in the eastern part of the district, where a foundry had been operational until the early 1980s. A cluster of leukaemia cases was observed in males in a northern part of the area, where no major sources of benzene seemed to be present.

Conclusions: The estimated risks seem to be slightly or not at all related to the distance from the coke oven. The statistically significant higher risks observed in males for NHL and leukaemia, and the clusters of leukaemia in males and of NHL in both sexes deserve further investigations in order to trace the exposures associated with such risks.
\end{abstract}

ए vidence of the carcinogenic effect of benzene in occupationally exposed workers has been reported since the 1920 s, ${ }^{1}$ but to date the specific sites of involvement have not been definitively assessed. ${ }^{2}$ While an excess risk from acute myeloid leukaemia (AML) is generally accepted, the risk of developing different kinds of leukaemia or other lymphohaematopoietic neoplasms is still debated. ${ }^{2}$ Several recent studies have evaluated the possible association between cancer and benzene at environmental concentrations, which are, in general, many orders of magnitude lower than those from occupational exposures. However, general populations are often exposed to chronic doses over longer time periods than workers. Moreover, occupational cohorts are not representative of the total population, in that they do not include either children or elderly people; women are also generally underrepresented. ${ }^{3-5}$

An ecological study carried out in Sweden ${ }^{6}$ found a positive association between car ownership and AML in persons aged under 25. This observation seemed to confirm the results of a similar analysis in the $\mathrm{UK}^{7}{ }^{7}$ which also reported a significant correlation between the number of cars per household and acute lymphoblastic leukaemia, chronic lymphoid leukaemia, low grade non-Hodgkin's lymphoma, and all lymphoproliferative diseases. On the contrary, a more complex study, carried out on the same UK database, ${ }^{8}$ after adjusting for socioeconomic status, failed to detect any association between the number of cars owned and acute lymphoblastic leukaemia.

Feychting and colleagues, ${ }^{9}$ using $\mathrm{NO}_{2}$ outdoor concentration as indicator of exposure to air pollutants, found an association between air pollution and childhood cancer, including leukaemia, even though statistical significance was not reached. The relative risks estimated for middle $\left(40-49 \mu \mathrm{g} / \mathrm{m}^{3}\right)$ and high $\left(>49 \mu \mathrm{g} / \mathrm{m}^{3}\right)$ concentration categories with respect to the reference $\left(\leqslant 39 \mu \mathrm{g} / \mathrm{m}^{3}\right)$ were 1.7 and 2.7 , respectively.

More recently, a study performed in the West Midlands, $\mathrm{UK}^{10}$ estimated a risk of 1.2 (95\% CI 0.7 to 1.7$)$ and $1.5(95 \%$ CI 0.7 to 2.9) for all leukaemias in children living near main roads and petrol stations, respectively, while a reanalysis of a study on children living in Denver ${ }^{11}$ reported a very high risk of leukaemia in subjects exposed to high concentrations of vehicular exhausts with respect to those living in low traffic areas (odds ratio $8.28,95 \%$ CI 2.09 to 32.80 ).

In recent years few studies have been conducted to evaluate the association between environmental concentrations of benzene and lymphopoietic cancers. A study on police motorcyclists in Rome found a higher risk of mortality for non-Hodgkin's lymphoma (NHL). ${ }^{12}$ Moreover, an excess of NHL mortality risk was also observed in filling station attendants in the Latium region in Italy (standardised mortality ratio 173), even if statistical significance was not reached. ${ }^{13}$

Although compelling evidence has yet to be fully substantiated, the rise of environmental concentrations of benzene and other toxic organic compounds from vehicular exhaust is suspected to be the main cause of the upward trend of NHL observed in the past half century in developed countries. ${ }^{14}$

There is no apparent tendency in the scientific literature to hold benzene accountable as a possible risk factor for

Abbreviations: $A A R$, age adjusted rate; $A M L$, acute myeloid leukaemia $\mathrm{Cl}$, confidence interval; FBE-SIR, full Bayes estimate of standardised incidence ratio; HD, Hodgkin's disease; NHL, non-Hodgkin's lymphoma; $\mathrm{PAH}$, polycyclic aromatic hydrocarbon; RR, relative risk; SIR, standardised incidence ratio 
Table 1 Sociodemographic characteristics of the area under study (Cornigliano) and of the two selected controls (Rivarolo and total municipality of Genoa) at the 1991 Italian national census

\begin{tabular}{lllllc}
\hline Area & ACR & LEL & IS & LOE & $\begin{array}{l}\text { Total } \\
\text { population }\end{array}$ \\
\hline Cornigliano & 197.8 & 81.6 & 27.8 & 62.4 & 16668 \\
Rivarolo & 177.3 & 76.5 & 20.3 & 54.1 & 38287 \\
Genoa & 226.1 & 65.4 & 15.5 & 42.3 & 678771 \\
\hline
\end{tabular}

$A C R$, aged child ratio percentage (people over 64 years divided by people under 15 years); LEL, low education level (percentage of people without any diploma or having obtained just a lower Italian middle school certificate); IS, percentage of immigrants from Southern Italy or islands; LOE, level of employment (percentage of unemployed or unskilled workers aged 15-64 years).

Hodgkin's disease (HD) ${ }^{2}$ or multiple myeloma, ${ }^{2}{ }^{15}$ even though some occupational studies have occasionally reported some excess of risk in exposed workers. ${ }^{2}{ }^{16}$ With regard to the possible effect of environmental concentrations on the risk of HD for the general population, one recent investigation detected an increasing risk of about $25 \%$ for HD (but not of other cancers) in children as a result of a doubling benzene concentration during pregnancy, with borderline statistical significance $(p=0.06) .{ }^{17}$ In addition, a large ecological study on the populations living around seven oil refineries sites in Great Britain, revealed a doubling in risk for HD within $0.5 \mathrm{~km}$ from the plants, ${ }^{18}$ even if no elevated risks for the other considered sites were pointed out. With regard to the risk for multiple myeloma, a statistically significant excess, which was higher in females (RR 2.01), was reported around a petrochemical facility in South Wales. ${ }^{19}$ However, this risk did not seem to decline with the distance from the plant, and no excess for other lymphohaematopoietic malignancies was reported.

This study aimed to evaluate the incidence risk of lymphohaematopoietic cancers in Cornigliano, a district of the Genoa (Italy) municipality where a coke oven, a well known industrial source of environmental benzene, ${ }^{5}$ is situated only about 300 metres from residential areas, and to analyse the spatial distribution of incidence risk for leukaemia and non-Hodgkin's lymphoma.

\section{MATERIALS AND METHODS}

\section{Characteristics of the areas under study}

Cornigliano is situated in the western part of Genoa, along the Ligurian Sea. The coastline is level, with hills extending northward and all around the residential area. The Cornigliano urban area covers $5.2 \mathrm{~km}^{2}$, corresponding to about $10 \%$ of the whole district, while $50 \%$ is covered by an industrial area that was reclaimed in the 1950s by filling the sea with debris from nearby hills. This new land was used to build an iron and steel factory, made up of a coke oven, blast furnaces, and plate rolling mills. The entire facility stretches for more than $1 \mathrm{~km}$ along the sea coast. The coke oven is located in the east of the steel plant and yields coke, which is then allotted to the blast furnace for the production of cast iron. From east to west a highly trafficked thoroughfare passes through the whole district. Finally, the extreme western subarea included a big foundry, that was operational until the early 1980s.

The populations of Genoa proper and of Rivarolo, the district more similar to Cornigliano with regard to sociodemographic characteristics, were selected as controls. Table 1 shows the distribution of demographic and socioeconomic characteristic (age, occupation, education, and immigration) of the areas under study.

Rivarolo lies to the north of Cornigliano, beyond a hilly barrier, and spread north-south for $2 \mathrm{~km}$ and nearly $5 \mathrm{~km}$ from
Table 2 Mean benzene concentration $\left(\mu \mathrm{g} / \mathrm{m}^{3}\right)$, standard deviation (SD), minimum (Min), and maximum (Max) values, and mean toluene/benzene $(t / b)$ ratio in Cornigliano and Rivarolo districts

\begin{tabular}{lllllrl}
\hline Area & Floors & Mean & SD & Min & Max & \multicolumn{1}{l}{ t/b } \\
\hline \multirow{2}{*}{ Cornigliano } & High & 10.3 & 4.8 & 2.8 & 20.5 & $1.0 \pm 0.7$ \\
& Low & 10.6 & 5.9 & 3.8 & 22.4 & $1.7 \pm 1.3$ \\
\multirow{2}{*}{ Rivarolo } & High & 4.4 & 2.2 & 1.9 & 9.6 & $2.4 \pm 0.7$ \\
& Low & 4.4 & 2.2 & 2.5 & 10.5 & $2.8 \pm 1.2$ \\
\hline
\end{tabular}

east to west. Thirteen per cent of the district is covered by urban area. The district is crossed from north to south by a highly trafficked street and by the Genoa-Milan motorway.

\section{Source of cases and populations}

All malignant haematological cancer cases (ICD-9: 200.0208.9) and myelodysplasias (ICD9: 238.7), diagnosed in the 1986-94 period in the areas under study, were drawn from the incidence data base of the Ligurian Cancer Registry. The corresponding populations at risk were estimated using the number of inhabitants by sex, age, class, and census tract, registered at the 1991 Italian national census and provided by the Statistical Office of Genoa municipality.

\section{Environmental pollution control}

Five conveyed benzene sources are present in the steel factory: four coke oven and one Cowper's chimneys; emissions from the two sources reach approximately $425 \mathrm{~g}$ and $220 \mathrm{~g}$ of benzene per hour, respectively.

Benzene concentrations in air (hourly mean) were measured from April 1998 to April 1999 in a fixed monitoring station operated by the Genoa Province, placed 330 metres downwind of the coke oven's centre. The annual mean benzene concentration measured by the fixed station was 15.1 (16.2) $\mu \mathrm{g} / \mathrm{m}^{3}$. Benzene concentration was strongly dependent on wind direction. The highest benzene concentration, 28 $\mu \mathrm{g} / \mathrm{m}^{3}$, was found with southeast winds, while the lowest, 3.2 $\mu \mathrm{g} / \mathrm{m}^{3}$, was found with northeast winds.

During the period 15-21 April 1999, an estimate of the mean weekly benzene concentrations outside 27 Cornigliano and 28 Rivarolo houses was simultaneously performed by the Environmental Chemistry Section of the National Cancer Research Institute of Genoa (Italy), ${ }^{20}$ using passive tubes placed outside residences. ${ }^{21}$ Unfortunately, this method did not allow an estimate of the exposure for the whole of either monitored area. In particular, with regard to Cornigliano, about $60 \%$ of its 65 census tracts were covered, mainly close to the coke oven, corresponding to $78 \%$ of the whole population. However, such measurements confirmed that benzene concentrations were higher in Cornigliano compared to Rivarolo (table 2 ). For $47 \%$ of the exposure time, sampling sites were downwind of the coke oven (winds from south and east-southeast). A significant difference was also observed in the mean toluene/benzene ratio: with southeast winds this value was 0.25 , very similar to that found in coke oven emissions; instead, the benzene and toluene composition in samples collected with northeast winds was different, their mean ratio being 3.6, similar to that found in automobile emissions. All these results confirmed that, with southeast winds, the fixed monitoring station and the urban area of Cornigliano lie downwind of the coke oven and the diffuse benzene emissions of this plant significantly increase the benzene concentration.

The meteorological information necessary for the evaluation of these measurements was obtained from a station of the Genoa Province placed in the hilly zone of Cornigliano. 
Table 3 Incidence of lymphohaematopoietic cancers in Cornigliano and the two control areas (1986-94); cases and age adjusted rates per 100000 inhabitants by sex, relative risks, and their $95 \%$ confidence intervals $(95 \% \mathrm{Cl})$

\begin{tabular}{|c|c|c|c|c|c|c|c|c|c|c|}
\hline & \multicolumn{2}{|c|}{ Cornigliano } & \multicolumn{2}{|l|}{ Rivarolo } & \multicolumn{2}{|l|}{ Genoa } & \multicolumn{2}{|c|}{$\begin{array}{l}\text { Cornigliano } v \\
\text { Rivarolo }\end{array}$} & \multicolumn{2}{|c|}{$\begin{array}{l}\text { Cornigliano v } \\
\text { Genoa }\end{array}$} \\
\hline & $\begin{array}{l}\text { Number } \\
\text { of cases }\end{array}$ & $\begin{array}{l}\text { Age adjusted } \\
\text { rates }\end{array}$ & $\begin{array}{l}\text { Number } \\
\text { of cases }\end{array}$ & $\begin{array}{l}\text { Age adjusted } \\
\text { rates }\end{array}$ & $\begin{array}{l}\text { Number } \\
\text { of cases }\end{array}$ & $\begin{array}{l}\text { Age adjusted } \\
\text { rates }\end{array}$ & $\begin{array}{l}\text { Relative } \\
\text { risk }\end{array}$ & $95 \% \mathrm{Cl}$ & $\begin{array}{l}\text { Relative } \\
\text { risk }\end{array}$ & $95 \% \mathrm{Cl}$ \\
\hline \multicolumn{11}{|l|}{ Males } \\
\hline Non-Hodgkin's lymphoma & 25 & 29.2 & 24 & 12.3 & 617 & 17.4 & 2.4 & 1.4 to 4.1 & 1.7 & 1.2 to 2.6 \\
\hline Hodgkin's disease & 5 & 6.8 & 8 & 4.8 & 132 & 4.3 & 1.4 & 0.4 to 4.2 & 1.5 & 0.6 to 3.8 \\
\hline Multiple myeloma & 8 & 8.7 & 14 & 6.9 & 273 & 7.1 & 1.3 & 0.5 to 3.1 & 1.3 & 0.6 to 2.6 \\
\hline Leukaemia & 20 & 25.3 & 19 & 10.0 & 443 & 12.4 & 2.4 & 1.3 to 4.5 & 1.9 & 1.2 to 3.0 \\
\hline Myelodysplasia & 6 & 6.5 & 18 & 8.7 & 267 & 6.9 & 0.8 & 0.3 to 1.9 & 1.0 & 0.4 to 2.2 \\
\hline Total & 64 & 76.5 & 83 & 42.6 & 1732 & 48.1 & 1.7 & 1.3 to 2.4 & 1.6 & 1.2 to 2.0 \\
\hline \multicolumn{11}{|l|}{ Females } \\
\hline Non-Hodgkin's lymphoma & 13 & 13.0 & 23 & 10.8 & 559 & 13.3 & 1.2 & 0.6 to 2.5 & 1.0 & 0.6 to 1.7 \\
\hline Hodgkin's disease & 3 & 4.5 & 3 & 1.6 & 96 & 2.9 & 2.3 & 0.5 to 11.4 & 1.3 & 0.4 to 4.1 \\
\hline Multiple myeloma & 2 & 1.7 & 10 & 4.6 & 245 & 5.4 & 0.4 & 0.1 to 1.9 & 0.3 & 0.1 to 1.4 \\
\hline Leukaemia & 4 & 3.9 & 23 & 11.4 & 390 & 9.4 & 0.4 & 0.1 to 1.1 & 0.4 & 0.2 to 1.2 \\
\hline Myelodysplasia & 3 & 2.9 & 11 & 4.7 & 258 & 5.7 & 0.6 & 0.2 to 2.0 & 1.7 & 1.2 to 2.6 \\
\hline Total & 25 & 26.0 & 70 & 33.2 & 1548 & 36.7 & 0.8 & 0.5 to 1.2 & 1.5 & 0.6 to 3.8 \\
\hline
\end{tabular}

\section{Statistical methods}

Age adjusted rates (AAR) per 100000 inhabitants were computed for all lymphohaematopoietic neoplasms (ICD-9: 200.0-208.9, 238.7) and for five selected sites: non-Hodgkin's lymphoma (ICD-9: 201.0-201.9, 202.0-202.9), Hodgkin's disease (ICD-9: 200.0-200.9), multiple myeloma (ICD-9: 203.0-203.9), leukaemia (ICD-9: 204.0-208.9), and myelodysplasia (ICD-9: 238.7). The 1991 census of the Italian population was selected as standard.

Relative risks (RR) and their related 95\% confidence intervals (CI) between the area under study (Cornigliano) and the two selected controls were estimated via Poisson regression model. ${ }^{22}$

Spatial trend of risk was evaluated by comparing cumulative standardised incidence ratios per 100 (cSIR) estimated within five concentric circles with a $500 \mathrm{~m}$ increment drawn around the coke oven. The related statistical significance was assessed by the Stone's test. ${ }^{23}$

The standard population utilised for the cSIR estimation was obtained by pooling together the Cornigliano and Rivarolo populations. Using the same standard population, the geographic pattern of incidence within Cornigliano was evaluated by computing full Bayes estimates of standardised incidence ratio per 100 (FBE-SIR) for each census tract, by the conditional autoregressive model proposed by Besag et al in $1991 .{ }^{24}$ In each census tract, the FBE-SIR represents an estimate of the incidence risk with respect to the selected standard, computed taking into account the possible correlation between such a risk and those from the adjacent sub-areas, and may be regarded as a smoothing function applied to the more common (maximum likelihood) SIR to reduce the variability due to small population. ${ }^{22}$

FBE-SIRs were computed by the WinBugs statistical package, ${ }^{25}$ which makes full Bayes estimates using the Gibb's sampler applied to Marcov chains Monte Carlo. ${ }^{26}$

Stone's test was performed using an ad hoc software program developed by Prof. Corrado Lagazio of the Department of Statistics of the University of Trieste (Italy). The remaining statistical analyses were performed using SPSS ${ }^{27}$ and GLIM $4.0^{28}$ statistical packages.

\section{RESULTS}

Table 3 shows incidence cases and AAR for the areas under study and the corresponding RR.

Cornigliano showed a statistically significant higher risk in males for all lymphohaematopoietic cancers, compared to both Rivarolo (RR 1.7) and Genoa (RR 1.6). Higher RR were also observed for NHL (RR $2.4 v$ Rivarolo and RR $1.7 v$ Genoa) and for leukaemia (RR $2.4 v$ Rivarolo and RR $1.9 v$ Genoa).

As far as females are concerned, statistically significant higher RR were not observed either for all lymphohaematopoietic neoplasms or for all selected sites, even though higher risks were found for NHL compared to Rivarolo (RR 1.2) and for HD compared to both control areas (RR $2.3 v$ Rivarolo and $1.3 v$ Genoa, respectively). The other selected sites showed higher or similar rates in the two control areas.

Table 4 shows the geographic trend of incidence risk for leukaemia and NHL by sex around the coke oven. In males no increased risk was observed for NHL near the coke oven, while the risk for leukaemia seemed to rise with increasing distance from the oven. Stone's test did not reveal any statistically significant trend.

In females a rising, even if statistically non-significant $(p=0.185$, Stone's test $)$, risk for NHL was observed approaching the plant, while a statistically significant increase in risk was observed for leukaemia, even if such a trend was due to just one case close to the coke oven, followed by zero cases in the second band (between 500 and $1000 \mathrm{~m}$ from the coke oven).

Figure 1 shows the pattern of incidence risk of NHL in males. In most parts of the district, FBE-SIR varied between 120 and 200 without showing any clear pattern, while in the extreme eastern part a cluster of higher risk (more than 200) was observed, due to four observed cases.

In females (fig 2), FBE-SIR of about 80-120 were observed in most of the considered area, except for the extreme eastern part where a higher risk was observed, due to one observed case in a sub-area with a small population. Higher risks, from 120 to 200 , were also observed in the southeastern area, in front of the coke oven, and in some other census tracts, especially in the central-southern part close to the district's main thoroughfare (even if in this latter case no clear pattern emerged).

Figure 3 shows the geographic pattern of leukaemia risk in males. Higher FBE-SIR were observed in the extreme west and in a small south-central sub-area. A cluster of higher incidence, corresponding to four census tracts, was observed in the extreme northern part of the district. The remaining FBE-SIR were between 160 and 200 in most central census tracts, and between 120 and 160 in southern and in eastern parts of the district. 
Table 4 NHL and leukaemia spatial trend: SIR at selected distance from the coke oven

\begin{tabular}{|c|c|c|c|c|c|c|c|c|}
\hline \multirow[b]{2}{*}{ Bands $(\mathrm{m})$} & \multicolumn{4}{|c|}{ Males } & \multicolumn{4}{|c|}{ Females } \\
\hline & Obs & SIR & cSIR & $\mathrm{p}$ & Obs & SIR & cSIR & $\mathrm{p}$ \\
\hline Non-Hodgkin's lymphoma & & & & 0.664 & & & & 0.185 \\
\hline$\leqslant 500$ & 1 & 117.1 & 117.1 & & 1 & 158.2 & 158.2 & \\
\hline $500-1000$ & 15 & 171.4 & 166.6 & & 8 & 125.0 & 128.0 & \\
\hline $1000-1500$ & 8 & 201.6 & 176.8 & & 4 & 125.2 & 127.1 & \\
\hline$>1500$ & 1 & 71.3 & 166.9 & & 0 & 0.0 & 113.8 & \\
\hline Leukaemia & & & & 0.898 & & & & 0.020 \\
\hline$\leqslant 500$ & 1 & 145.4 & 145.4 & & 1 & 195.3 & 195.3 & \\
\hline $500-1000$ & 9 & 127.4 & 129.0 & & 0 & 0.0 & 18.5 & \\
\hline $1000-1500$ & 7 & 225.2 & 156.6 & & 2 & 91.9 & 39.6 & \\
\hline$>1500$ & 3 & 275.2 & 167.4 & & 1 & 125.3 & 47.8 & \\
\hline
\end{tabular}

Obs, observed cases; SIR, standardised incidence ratio; cSIR, cumulative SIR; $p$, statistical significance of spatial trend (Stone's test).

The small number of leukaemia cases observed in females did not allow us to estimate the FBE-SIR or to evaluate the corresponding geographic pattern.

\section{DISCUSSION}

Differences in benzene concentrations measured in Cornigliano versus Rivarolo and the lower toluene/benzene ratio observed in the former area, particularly in the high floors, confirmed that the coke oven was the main benzene source in the district. Coke ovens are a well known industrial source of benzene and other environmental pollutants, including polycyclic aromatic hydrocarbons (PAHs). ${ }^{5}$ In particular, a previous investigation in the Genoa municipality, covering the 1994-95 calendar period, indicated that the coke oven in Cornigliano was also the main responsible source of the high concentrations of benzo(a)pyrene in the area. ${ }^{29}$ However, since benzene related PAHs are thought to be more associated to lung cancers and some other neoplasms, ${ }^{514}$ the present investigation focused mainly on the possible association between environmental benzene pollution and lymphohaematopoietic cancers.

In the study period, 89 incidence lymphohaematopoietic cancer cases were observed in the district of Cornigliano, of which 62 were either leukaemia or NHL, accounting for nearly $70 \%$ of the total number of cases. The small number of cases observed for the other sites considered makes comparison of the results from the two control areas difficult to evaluate. For instance, the risk for Hodgkin's disease for females living in

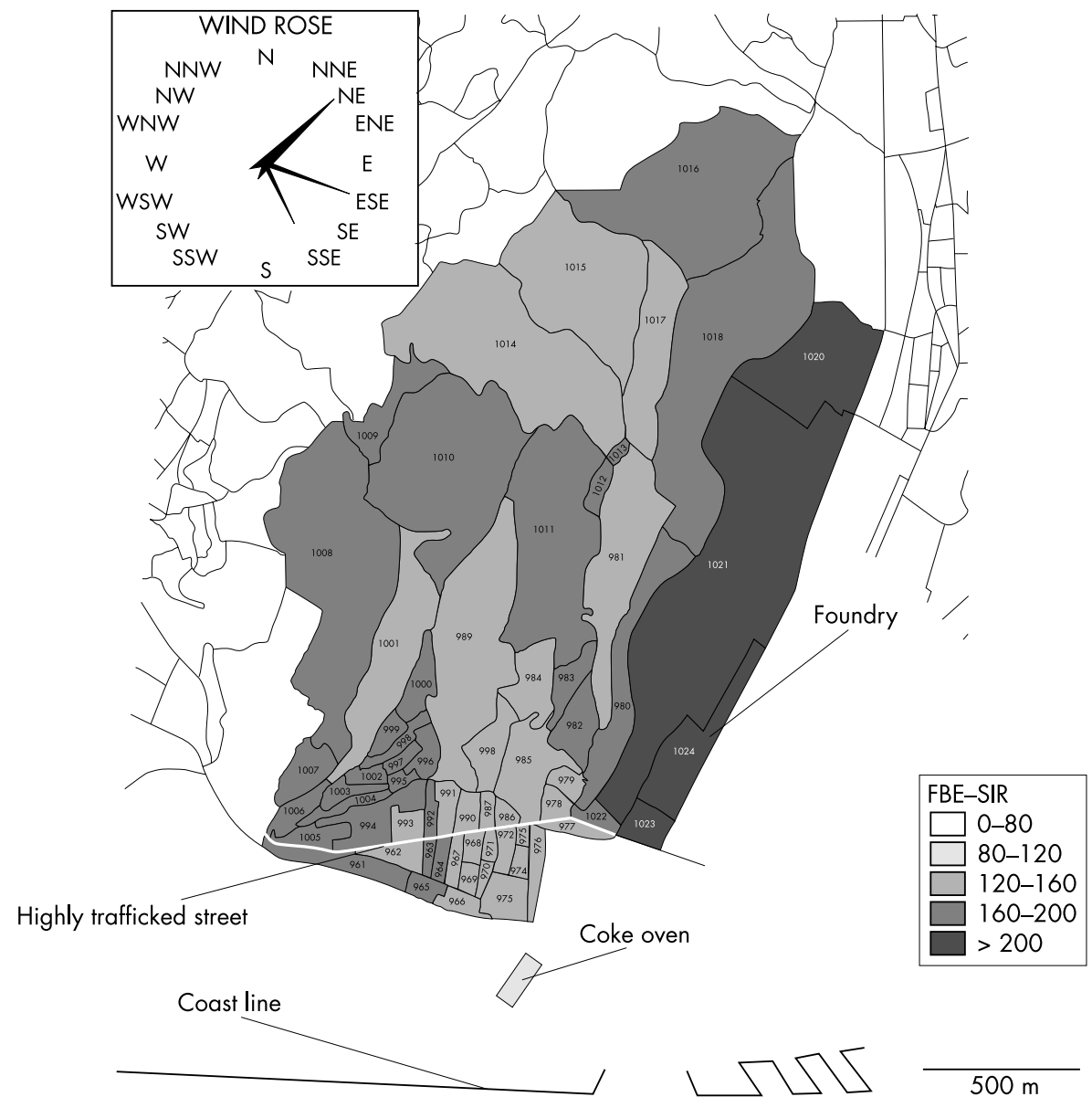

Figure 1 Pattern of incidence risk of non-Hodgkin's lymphoma in Cornigliano area (males). 


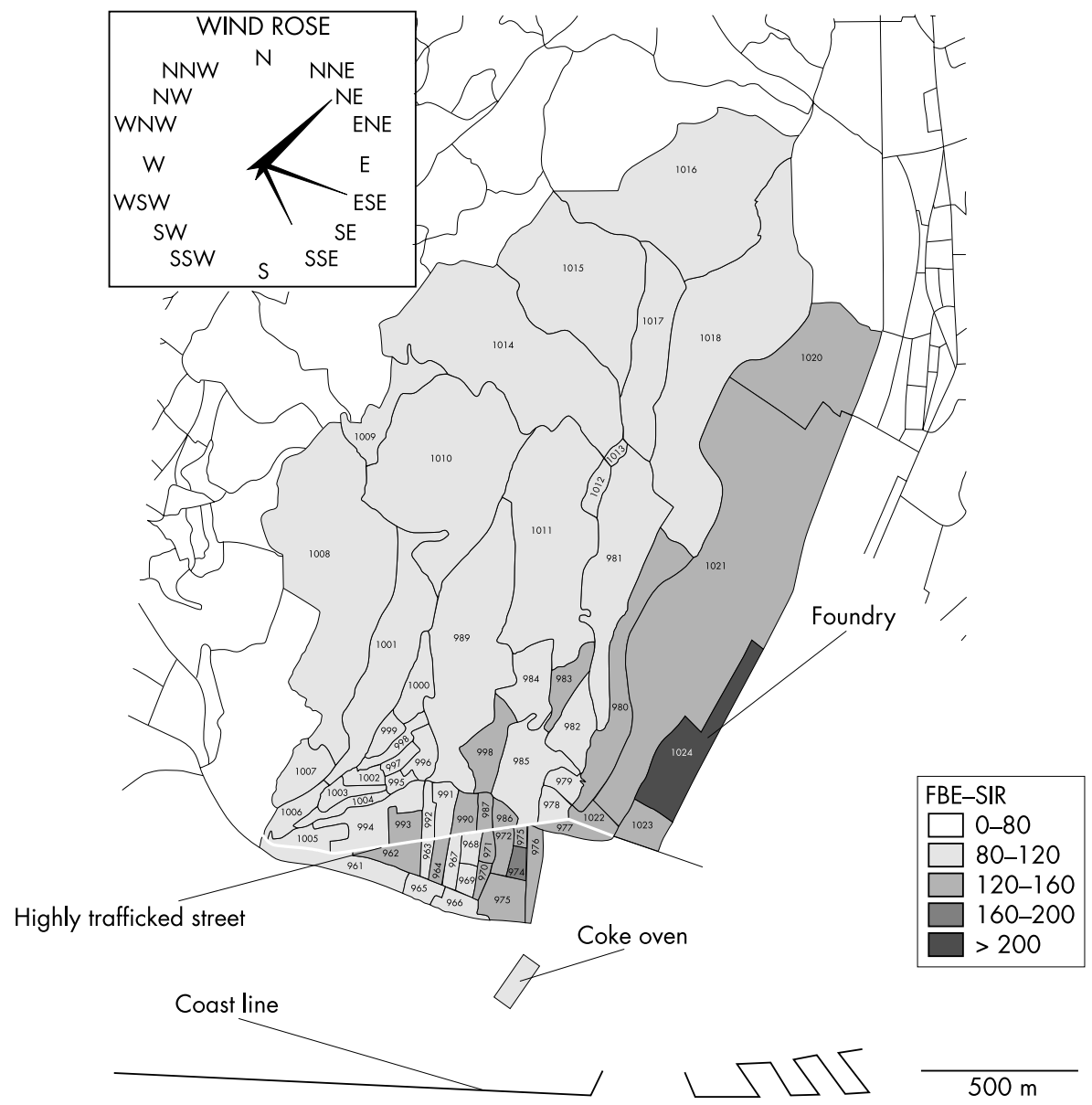

Figure 2 Pattern of incidence risk of non-Hodgkin's lymphoma in Cornigliano area (females).

Cornigliano was 1.3 times higher than the risk of the corresponding population of Genoa proper and more than twice that of Rivarolo. This excess incidence was caused by only three cases observed in Cornigliano, and it is impossible, especially in a descriptive context, to state whether the lack of statistical significance was a result of low statistical power or the absence of any real effect. For these reasons, this study endeavoured to evaluate the risk pattern for the two more common lymphohaematopoietic sites.

In the district of Cornigliano, a statistically significant higher risk for leukaemia was observed in males, showing a tendency to be higher versus the population of Rivarolo than versus the population of Genoa proper. This difference is in agreement with the hypothesis of a slight protective effect of deprivation index variables on the risk of leukaemia, suggested for some European areas, including Turin in Italy, ${ }^{30}$ even if the related $95 \%$ confidence intervals are largely overlapped.

Although leukaemia is recognised to constitute a group of several diseases with possibly different aetiological factors, ${ }^{15}{ }^{31}$ we opted to analyse the risk for the entire category because of the small number of observed cases. A common objection to such an approach is that leukaemia types other than AML seem to be less associated with benzene exposure. ${ }^{611}$ However, in the Cornigliano population two cases of AML were observed during the period analysed; any analysis of such a subgroup would therefore yield unreliable results.

A higher risk of leukaemia with respect to Rivarolo was also observed in male children (under 15); the estimated RR were 4.6 versus Rivarolo and 3.6 versus Genoa (data not shown). These estimates, however, based only on two cases in males, do not enable us to draw reliable conclusions. Furthermore, there seems to be no relation between the residence of these cases and the coke oven (data not shown).
A higher incidence was also observed for NHL in males. The lack of an excess risk in females, for both leukaemia and NHL, could suggest an effect due to occupational exposure, which is more likely to occur in males. The lower risk for leukaemia in females, even if not statistically significant, remains difficult to interpret.

To our knowledge, there is little evidence in the scientific literature of a different effect by gender of chronic exposure to benzene. Women are under-represented in occupational studies, but their higher body fat ratio and their tendency to metabolise benzene more effectively than men should indicate a higher risk for such a group. ${ }^{142}$ It is not clear, however, whether these factors also play a negative role under chronic low exposure.

As far as children are considered, the higher incidence of leukaemia in males, observed in most countries around the world, ${ }^{33}$ was suggested to be due more to higher exposure from different activity patterns, such as time spent in garages and workshops or an intensive use of consumer products containing benzene, rather than to a higher susceptibility to the pollutant. ${ }^{34}$ Nevertheless, a different behaviour of male children living in Cornigliano with respect to those living in the control area, seems to be unlikely. In addition, a recent study conducted in Rome found a higher risk for leukaemia in children, particularly males, living within 150 metres of heavily trafficked thoroughfares. ${ }^{35}$

Benzene concentrations outside Cornigliano residences suggest that people living along the area downwind of the coke oven are likely to be more heavily exposed to environmental benzene than people living in other Cornigliano areas or in Rivarolo. However, in most of the studies aimed to estimate the risk of leukaemia associated with highly trafficked roads, a distance under $200 \mathrm{~m}$ is usually employed..$^{1035}$ Therefore, the impact of benzene from the coke 


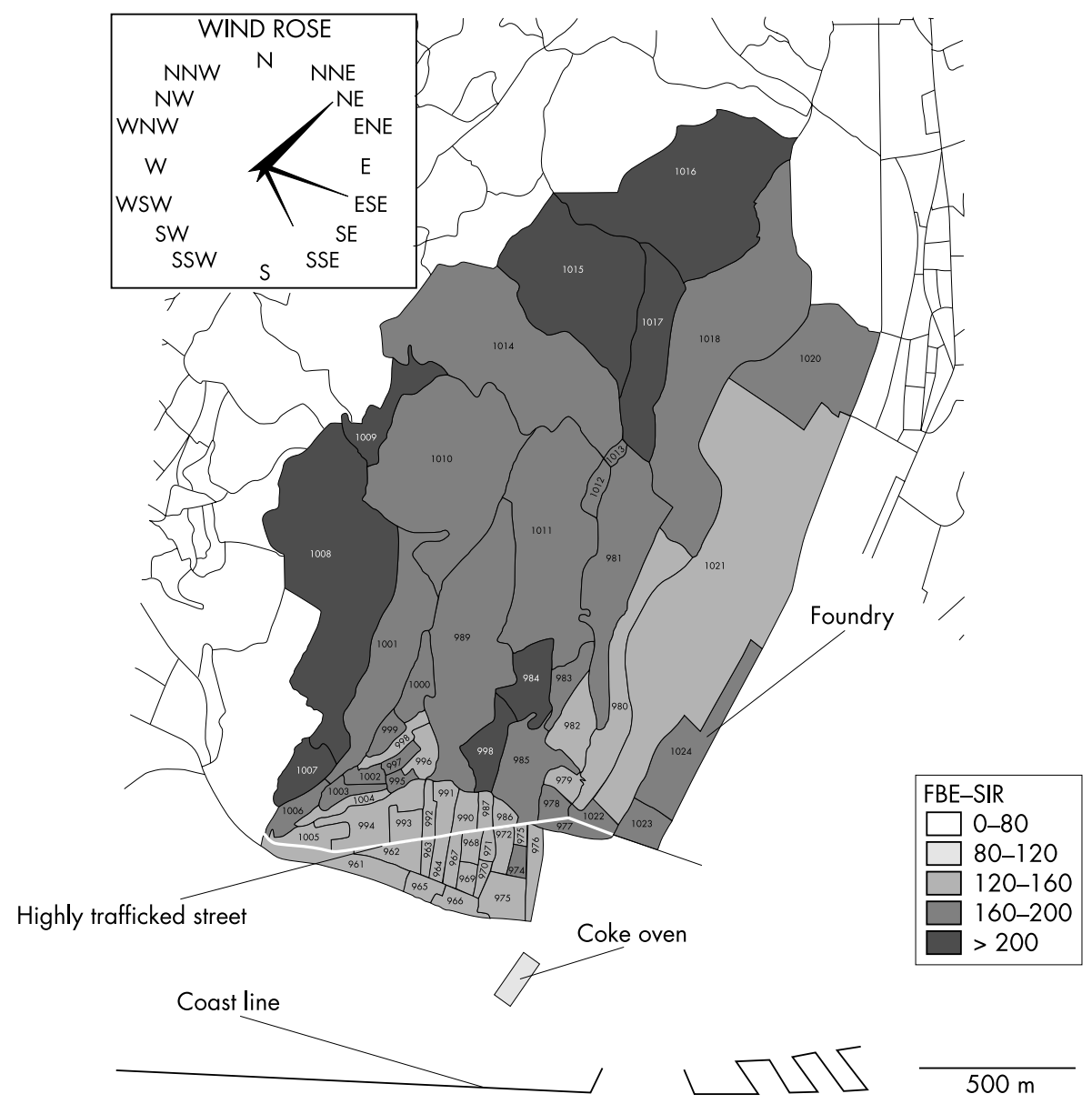

Figure 3 Pattern of incidence risk of leukaemia in Cornigliano area (males).

oven, which is located roughly 300 metres from the residential area, might concern only a small part of the population; this would make the results from the spatial trend analysis difficult to interpret, especially without accurate measurements of air benzene concentrations. In particular, one case of leukaemia observed in a female residing in the first circle around the coke oven $(0-500 \mathrm{~m})$, even if accounting for a nearly doubled risk, is hard to ascribe to environmental pollution. Furthermore, the instability of a risk estimated on only one case does not allow any clear cut conclusions to be drawn.

The geographic pattern of risk emerging from the FBE-SIR maps is consistent with the results from the spatial trend analyses and did not highlight any cluster of cases around the source of benzene. In males the risk of leukaemia seems to be higher in the extreme west and in northern subareas, very far from the coke oven and in the hilly part where no other major sources of benzene seem to be present, and might at least partially reflect the distribution of dwellers who are occupationally exposed to benzene or other toxic chemicals.

With regard to NHL, a cluster of risk was observed in the extreme eastern part of the area under study, both for males and for females. Interestingly, the higher FBE-SIR was observed in a census tract, where a foundry, another possible source of industrial pollution, was operational until the early 1980s. The lack of risk for leukaemia in this area might be due either to exposure to pollutants other than benzene, or to cohort effects resulting from different lag times between exposure and disease occurrence.

It seems unlikely that the prevailing winds, reported on the figures, influenced the observed patterns of risk. In fact, excluding northern winds, which are expected to blow the coke oven emissions far from the residential area, easterly winds prevailed; therefore, the central, rather than the western subarea would have been expected to show the highest risks for the considered diseases. However, we evaluated the trend of risk around the coke oven using Stone's method ${ }^{23}$ without including wind direction in the analyses, since the collection of such information in the studied area was begun only in 1994 at the end of the period under examination. Moreover, the presence of the sea coast may create local breezes, thus making it hard to estimate the influence of the wind on the distribution of pollutants. ${ }^{36}$ Furthermore, the difficulty in obtaining reliable measures of exposure is a problem commonly encountered in ecological investigations. ${ }^{37}$ For example, in a study cited above, ${ }^{19}$ carried out in an area of South Wales close to a petrochemical facility and with elevated leukaemia rates, monitoring data found no increased levels of benzene near the plant.

Finally, inspection of the geographic risk distribution, as shown in figs 1, 2, and 3, did not reveal any particular pattern close to the main Cornigliano thoroughfare, thus excluding a major confounding effect of motor vehicular exhaust.

\section{CONCLUSIONS}

The main finding of the present study is the detection of statistically significant higher risks for leukaemia and NHL for males living in an industrialised area. However, the lack of higher risks in females and the pattern of geographic distribution of NHL and leukaemia in both sexes do not suggest any association between the location of the coke oven and the residence of the cases.

Ecological studies, as is this investigation, aim to identify areas at higher risk for selected disease. Because they make use of routinely collected data, they are not costly and may be carried out over a short time. Moreover, ecological comparisons have been recognised as the first natural approach to study the long term effects of air pollution, due to the nature of the exposure and to measurement related problems. ${ }^{37}$ Their 


\section{Main messages}

- There was an increased incidence of cases for leukaemia and $\mathrm{NHL}$ among males living in an urban area where a coke oven is located a few hundred metres from the house.

- Such risks seemed to be slightly or not at all related to the location of the facility.

- The geographic pattern of risk for NHL in both sexes suggested the presence of a cluster in a subarea where a big foundry was operational until the early 1980s.

- Further studies are needed to trace the exposures associated with the observed risks and with their geographic distribution.

\section{Policy implications}

- Several other studies have pointed out an excess risk either for cancer or for other severe diseases in populations living near industrial plants. Scientific community and health services should promote investigations aimed at determining the exposures responsible for such risks and at reducing them in the years to come.

main limit is the inability to assess personal exposure; as a result, causal inference may not be drawn. In fact, the attribution of the exposure levels in an aggregated way may cause the well known "ecological fallacy" - that is, either a systematic under- or overestimation of the association under study. ${ }^{22} 38$ Furthermore, risks from environmental concentrations of benzene are likely to barely exceed the risk of the general population, and thus the low statistical power makes it hard to detect differences in risk distribution. ${ }^{4}$

Finally, benzene is a very common air pollutant given off by several sources. ${ }^{44}{ }^{39}$ The Rivarolo control area was selected because of the similarity of its sociodemographic characteristics with the Cornigliano area. A different pattern of exposure due to personal habits may thus be considered unlikely. However, a different distribution of occupational exposures, due to a tendency of workers to live near their workplace, cannot be ruled out. In light of such considerations, further investigation, in particular via epidemiological-aetiological studies, are needed in order to trace the exposures that may have contributed to the observed risks and to their geographic distribution.

\section{ACKNOWLEDGEMENTS}

We thank the Genoa Municipality, which provided us with data about the population (Dr Arvati, Statistical Unit and Dr Romani, Civil Status Offices) and geographic maps (Mr D'Orazi, Territorial Informative System); the Provincial Councillorship, which furnished the data about benzene concentrations and winds (Dr Brescianini, Environmental Control Centre); Dr Fontana of the National Cancer Research Institute of Genova (Italy) and Prof. Cislaghi of the Statistics and Biometrics Institute, University of Milan (Italy) for their excellent methodological advice; and Ms Barbieri, who collaborated in processing the maps in electronic format. Finally, our deep gratitude is extended to Prof. Lagazio of the Statistics Department of the University of Trieste (Italy), who implemented the statistical routine for Stone's test. This investigation was partially funded by the Ministry of University and Scientific Research (through the 1997-98 programme of the research of relevant national interest).

\section{Authors' affiliations}

S Parodi, E Stagnaro, Environmental Epidemiology Department,

National Cancer Research Institute, Genoa, Italy

M Vercelli, Tumour Registry Section, National Cancer Research Institute, Genoa; and Department of Oncology, Biology and Genetics, University of Genoa

A Stella, F Valerio, Environmental Chemistry Section, National Cancer Research Institute, Genoa

S Parodi and M Vercelli contributed equally to this work

\section{REFERENCES}

1 International Agency for Research on Cancer. IARC monograph on the evaluation of the carcinogenic risk of chemicals to humans. Some industrial chemicals and dyestuffs. Lyon, France: World Health Organization, International Agency for Research on Cancer, 1982:94-148

2 Savitz DA, Andrews KW. Review of epidemiologic evidence on benzene and hematopoietic cancers. Am J Ind Med 1997;31:287-95.

3 Woodruff TJ, Caldwell J, Cogliano VJ, et al. Estimating cancer risk from outdoor concentrations of hazardous air pollutants in 1990. Environ Res 2000;82:194-206

4 Duarte-Davidson R, Courage C, Rushton L, et al. Benzene in the environment: an assessment of the potential risk to health of the population. Occup Environ Med 2001;58:2-13.

5 Westley-Wise VJ, Stewart BW, Kreis I, et al. Investigation of cluster of leukemia in the Illawarra region of New South Wales, 1989-96. Med J Aust 1999;171:178-83

6 Nordlinder R, Järvholm B. Environmental exposure to gasoline and leukemia in children and young adults - an ecology study. Int Arch Occup Environ Health 1997;70:57-60.

7 Wolff SP. Correlation between car ownership and leukaemia: is non-occupational exposure to benzene from petrol and motor vehicle exhaust a causative factor in leukaemia and lymphoma? Experientia 1992;48:301-4.

8 Alexander FE, Leon DA, Cartwright RA. Isolation, car ownership and small area variation in incidence of acute lymphoblastic leukaemia in children. Paediatric Perinatal Epidemiol 1996;10:411-17.

9 Feychting $M$, Svensson D, Ahlborn A. Exposure to motor vehicle exhaust and childhood cancer. Scand J Work Environ Health 1998;24:8-1 1.

10 Harrison RM, Leung PL, Somervaille L, et al. Analysis of incidence of childhood cancer in the West Midlands of the United Kingdom in relation to proximity to main roads and petrol stations. Occup Environ Med 1999:56:774-80

11 Pearson RL, Wachtel H, Ebi KL. Distance weighted traffic density in proximity to a home is a risk factor for leukemia and other childhood cancers. J Air Waste Manag Assoc 2000;50:175-80.

12 Forastiere F, Perucci CA, Di Pietro A, et al. Mortality among urban policemen in Rome. Am J Ind Med Health 1994;26:785-98.

13 Lagorio S, Forastiere F, lavarone I, et al. Mortality of filling station attendants. Scand J Work Environ Health 1994;20:331-8.

14 O'Connor SR, Farmer PB, Lauder I. Benzene and non-Hodgkin's lymphoma. J Pathol 1999;189:448-53

15 Bergsagel DE, Wong $\mathrm{O}$, Bergsagel PL, et al. Benzene and multiple myeloma: appraisal of the scientific evidence. Blood 1999:4:1174-82.

16 Swaen GM, Slangen JM, OH MG, et al. Investigation of a cluster of ten cases of Hodgkin's disease in an occupational setting. Int Arch Occup Environ Health 1996;68:224-8.

17 Raaschou-Nielsen O, Hertel O, Thomsen BL, et al. Air pollution from traffic at the residence of children with cancer. Am J Epidemiol $2001 ; 153: 433-43$

18 Wilkinson P, Thakrar B, Walls P, et al. Lymphohaematopoietic malignancy around all industrial complexes that include major oil refineries in Great Britain. Occup Environ Med 1999;56:577-80.

19 Sans S, Elliott P, Kleinschmidt I, et al. Cancer incidence and mortality near the Baglan Bay petrochemical works, South Wales. Occup Environ Med 1995;52:217-24

20 Valerio F, Stella A, Izzotti A, et al. L'inquinamento atmosferico nella città di Genova: studio dell'esposizione a benzene. In: Ugazio G, ed. Atti XV Convegno PTAO, Turin: Università di Torino, 1999:121-41.

21 Valerio F, Pala $M$. Isoconcentration maps of BTX in the atmosphere of La Spezia (ltaly). Fresenius Environ Bull 1998;7:202-6.

22 Estève J, Benhamou R. Statistical methods in cancer research volume IV-Descriptive epidemiology. IARC Scientific Publication no. 128. Lyon International Agency for Research on Cancer, 1994.

23 Stone RA. Investigations of excess environmental risks around putative sources: statistical problems and a proposed test. Stat Med 1988;7:649-60

24 Besag J, York J, Molliè A. Bayesian image restoration with two applications in spatial statistics (with Discussion). Annals of the Institute of Statistical Mathematics 1991:49:1-59.

25 Spiegelhalter DJ, Thomas A, Best NG. WinBUGS version 1.3 User's Manual. Cambridge: MRC Biostatistics Unit, 2000

26 Mollié A. Bayesian mapping of disease. In: Gilks WR, Richardson S, Spiegelhalter DJ, eds. Markov Chain Monte Carlo in practice. Boca Raton/London/New York/Washington DC: Chapman \& Hall, 1996:359-79.

27 SPSS Inc. SPSS 9.0 User's Guide. Chicago, IL: SPSS Inc., 1999

28 Francis B, Green M, Payne C. GLIM 4.O. the statistical system for generalized linear interactive modelling. Oxford: Oxford University Press, 1994.

29 Valerio F, Pala $M$, Lazzarotto A, et al. Air quality standard for benzo(a)pyrene (BaP) in Genoa (1994-95). Polycycl Aromat 1996;9:41-66

30 Faggiano F, Partanen T, Kogevinas $M$, et al. Socioeconomic differences in cancer incidence and mortality. In: Kogevinas $M$, Pearce N, Susser $M$, Boffetta P, eds. Social inequalities and cancer. Lyon: International Agency for Research on Cancer, 1997:65-176.

31 Järvholm B, Forsberg B. Childhood cancer and possible exposure to benzene from traffic and petrol stations. Occup Environ Med 2000;57:500-4.

32 Brown EA, Shelley ML, Fisher JW. A pharmacokinetic study of occupational and environmental benzene exposure with regard to gender. Risk Anal 1998;18:205-13. 
33 Parkin DM, Kramàrovà E, Draper GJ, et al. International incidence of childhood cancer. Vol. II. Lyon: International Agency for Research on Cancer, 1998

34 Raaschou-Nielsen O, Lohse C, Thomsen BL, et al. Ambient air levels and the exposure of children to benzene, tolvene, and xylenes in Denmark. Environ Res 1997:75: 149-59.

35 Michelozzi P, Capon A, Barca A, et al. Esposizione a traffico ed incidenza di tumori del tessuto linfatico ed ematopoietico nei bambini a Roma [abstract]. In: Arie di città: la qualità dell'aria in ambiente urbano. Bologna, 2000
36 Brescianini C, Daminelli E, Miroglio D, Zero F. Rapporto annuale di qualità dell'aria - 1999 [technical report]. Genova, Italy: Provincia di Genova, Centro Operativo Provinciale, 1999: 91-5.

37 Katsouyanni K, Pershagen G. Ambient air pollution exposure and cancer. Cancer Causes Control 1997;8:284-91.

38 Webster T. Commentary: Does the spectre of ecologic bias haunt epidemiology? Int J Epidemiol 2002;31:161-2.

39 Wallace LA. Major sources of benzene exposure. Environ Health Perspect 1989;82:297-314

$\mathrm{ECHO}$

\section{Low level $\mathrm{CO}$ poisoning is a hidden danger to an unsuspecting public}

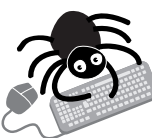

Please visit the Occupational and

Environmental Medicine website [www. occenvmed. com] for link to this full article. eople's health in the UK is threatened by low level exposure to carbon monoxide (CO) and will continue to be until a simple test is developed to confirm CO poisoning, according to a recent review.

Without a reliable biochemical marker all we will see in individual cases and populations will be "just the tip of the iceberg". There is already sufficient evidence from population studies, the review's author believes, for research to determine whether the threshold amount of atmospheric CO currently considered safe is indeed so.

For now, accident and emergency staff have to rely on vigilance in correctly diagnosing chronic CO poisoning - that is, repeated exposure, usually to low amounts of the gas. Occult poisoning-usually by chronic low level exposure-may not be recognised until repeated presentations with the same symptoms. CO poisoning is easily overlooked, because even classic signs and symptoms suggest many other possible diagnoses. Many factors confound the diagnosis, among them endogenous carboxyhaemoglobin (COHB) and COHB from atmospheric pollution and from smoking. COHB itself is poorly related to symptoms, and its accurate measurement is difficult and insufficiently researched.

The epidemiology of CO poisoning is similarly ill defined. Descriptive studies have provided sporadic evidence; population studies are dogged by other confounding environmental influences. Nevertheless, a steady decline in deaths attributed to CO poisoning in the US during 1979-1988 coincided with a 90\% drop in CO emissions from cars. In patient group studies CO amounts as low as $4-5 \%$ limit work capacity and maximal oxygen consumption in healthy people.

A Emergency Medical Journal 2002;19:386-390. 